\title{
DESTRUCTIVE TESTING OF THE WELD JOINTS ON SPLIT SLEEVE FOR BRANCH CONNECTIONS REPAIRS
}

New type of repairing technology for branch connection defects on gas pipelines has been designed recently. Repairing technique is based on manufacturing of split sleeve and welding of its parts together and to the repaired pipes by manual metal arc welding technology. Appropriate testing has to be performed to ensure practical and permanent use of such kind of sleeve in commercial area. Destructive testing was performed to confirm quality of the welds on the prototype sleeve repair. Macrostructural and hardness evaluation showed inhomogeneity present in some welds. According to that, microstructure observations, spectral analysis and mechanical tests were performed on the base metal of the sleeve. It has been showed that even when some problems may be present, repairing technique by split sleeve can be still suitable for permanent repairs of the defects of the branch connections.

Keywords: Destructive testing, macrostructural analysis, split sleeve, Vickers hardness, weld joint.

\section{Introduction}

Quality of weld joints is very important factor to ensure safety and long term lifetime of the gas transport pipelines. According to European Gas Pipeline Incident Data Group (EGIG) are construction defects (where weld joint defects also belongs) and material failures the third most frequent cause of the pipeline incidents [1]. Welding quality control is thus important and every new type of weld joint has to be analyzed by non-destructive evaluation and it also should be tested by destructive testing methods.

Numerous kinds of repair techniques are now available including the cut out and replace of the pipeline, construction of the bypass along the damaged area, grinding, weld deposition, metallic or composite sleeves [2]. Although the repairing techniques for straight parts of pipelines are well established, only a few of them are applicable for branch connections defects (e.g. defects in the area of fillet weld between header and branch pipe). Recently a new kind of split sleeve for such defects repairs has been designed [ 3 and 4]. Relatively complicated construction together with different manufacturing processes of sleeve parts might cause weld joint problems and precise weld examination is necessary. Non-destructive examination of weld joints has been proposed by ultrasonic technique TOFD [5] but destructive testing of such welds has not been proposed yet.
The aim of presented article is to perform the destructive testing of weld joints on split sleeve for branch connection repairing. Macrostructural analysis and hardness evaluation is presented together with selected base metal examinations.

\section{Experimental measures and results}

Weld joint analysis has been performed on the split sleeve for branch connections repairs (Fig. 1). Split sleeve consists of cylinder part and sphere-like part, which has to ensure safe installation of the sleeve to the repaired branch connection. Such type of split sleeve is joined together by butt welds and to the repaired pipes it is connected by circumferential fillet welds.

Different manufacture processes and also semi-finished products were applied to parts of the sleeve. Cylindrical part was prepared by welding of end plates to thick-walled pipe (thickness of $16 \mathrm{~mm}$ for each part). Both end plates are made of S355J2+N steel and material of the thick-walled pipe is $\mathrm{S} 355 \mathrm{~J} 2 \mathrm{H}$ steel. Segments of the sphere-like part were made by machining of S355JR steel block to required shape and size. Machined part was after that split to two segments. Materials used in this type of construction ensured weldability without additional conditioning. Weld joints were prepared by manual metal arc (MMA) welding technique.

\footnotetext{
* Marek Patek, Augustin Sladek, Milos Mician

Department of Technological Engineering, Faculty of Mechanical Engineering, University of Zilina, Slovakia

E-mail: marek.patek@fstroj.uniza.sk
} 


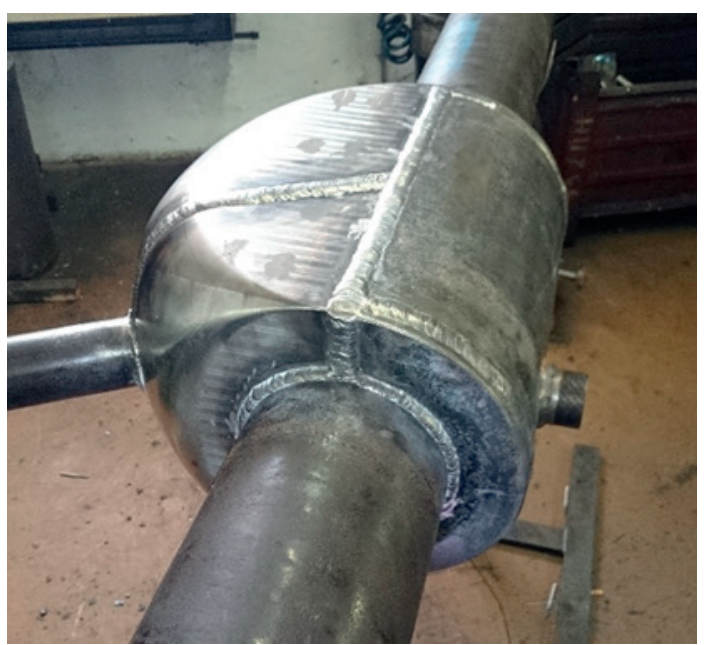

Fig. 1 Split sleeve for branch connection repairs

\subsection{Macrostructural analysis of weld joints}

Macrostructural analysis of the split sleeve weld joints was performed in terms of the EN ISO 17639 standard. Four characteristic welds were selected to analysis. Macrographs of the butt weld joints are shown in Fig. 2 and 3. Unacceptable defects were not detected neither on the macrographs of the butt joint between cylindrical and sphere-like part (Fig. 2) nor in the macrograph of weld joint between sphere-like segments of the sleeve (Fig. 3). Some imperfections might be observed such as linear misalignment or excessive penetration. Dimensions of these imperfections are within the allowed range according to standards (ISO 5817-B). In the lower part of the Fig. 2 and 3 the sealant carriers can be seen, which serve to carry a sealants that isolates the places of welding from places where leaking gas is present. Large size of the root opening can be seen between the sealant carrier and wall of the sleeve in macrograph shown in Fig. 3. Weld joint between the sealant carrier and split sleeve wall are only supplementary and after the sleeve is welded onto the pipeline, it has no function. Such kind of defect might be consider as acceptable for the functionality of the split sleeve. Macrostructural evaluation of the weld between the cylindrical and sphere-like part (Fig. 2) shows significant heterogeneity of the joint, which might be a sign of inappropriate microstructure and also mechanical properties of the base metal.

Typical macrographs of the girth fillet welds are shown in Fig. 4 and 5. Fillet welds do not show the presence of unacceptable defects similarly to the butt welds. Base metal and heat affected zone on the side of the sphere-like part also pointed out different character of macrostructure (Fig. 4) that confirms weld joint heterogeneity.

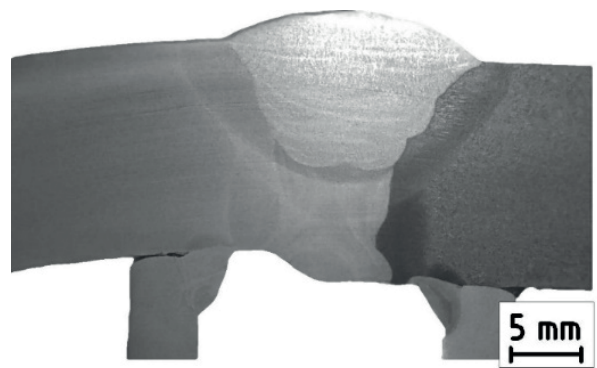

Fig. 2 Macrograph of butt weld joint between cylindrical (left) and sphere-like (right) part of the sleeve

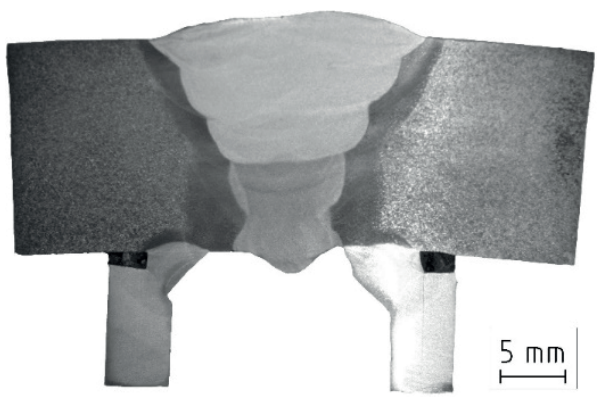

Fig. 3 Macrograph of butt weld joint between sphere-like parts of the sleeve

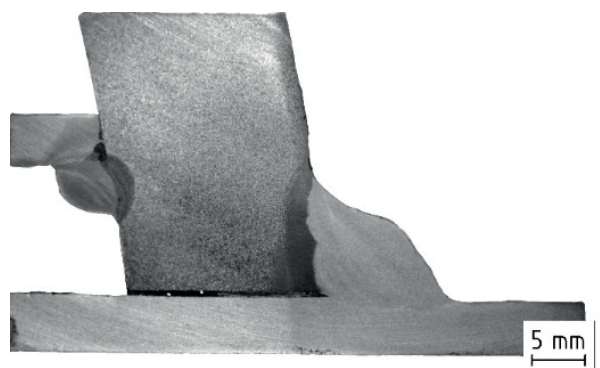

Fig. 4 Macrograph of fillet weld joint between sphere-like part of the sleeve and pipe

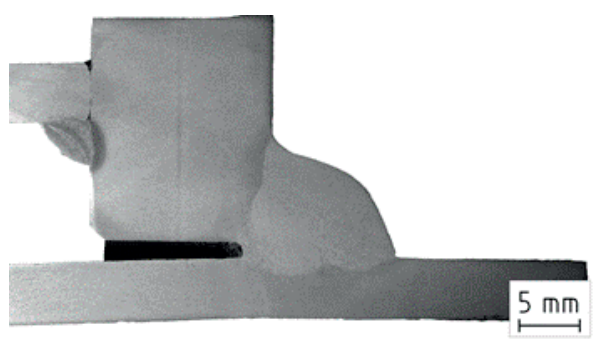

Fig. 5 Macrograph of fillet weld joint between cylindrical part of the sleeve and pipe

\subsection{Hardness measuring}

Vickers hardness method (HV10) was used to evaluate the weld joints hardness. Measuring was performed in terms of EN 
ISO 9015-1 standard. Significant increase of Vickers hardness can be seen in heat affected zone (HAZ) of the weld on the spherelike side of weld joint (Fig. 6 - 8). In these areas hardness reaches values higher than $300 \mathrm{HV}$ and in some cases it almost reached maximal allowed value for this type of material ( $380 \mathrm{HV}$ without heat treatment according to EN ISO 15614-1 standard). Hardness of weld joint on the side of cylindrical part of the sleeve did not significantly increase in HAZ (Fig. 6, 8 and 9).

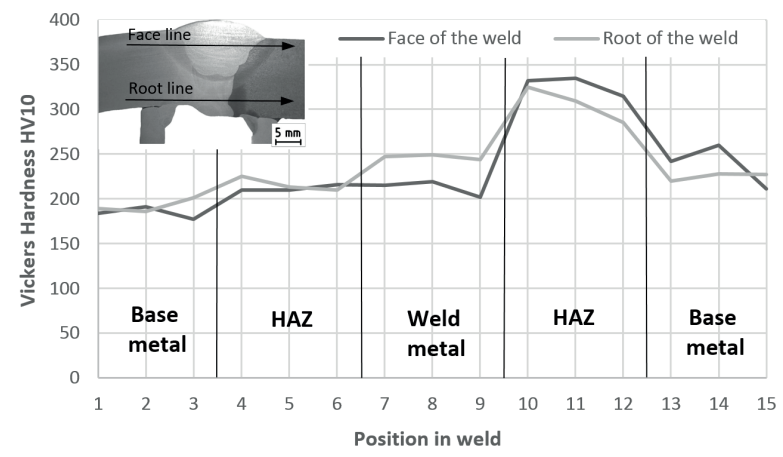

Fig. 6 Hardness of butt weld joint between cylindrical and sphere-like part of the sleeve

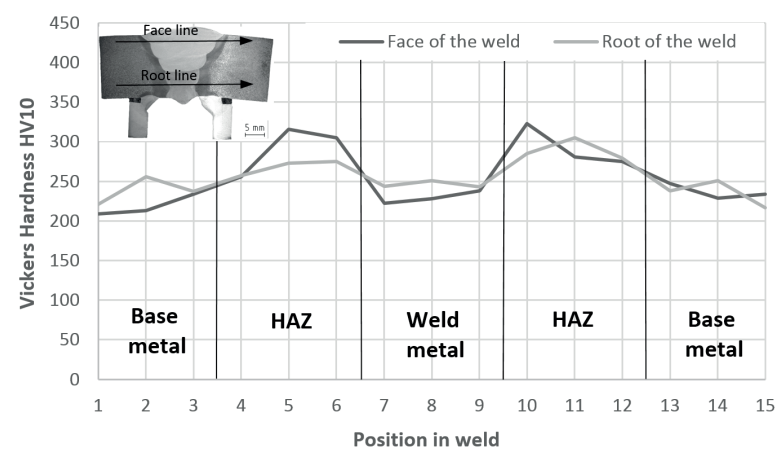

Fig. 7 Hardness of butt weld joint between sphere-like parts of the sleeve

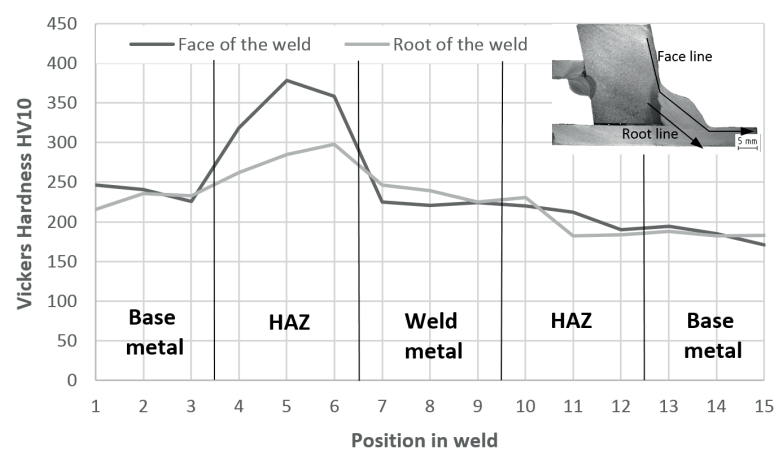

Fig. 8 Hardness of fillet weld joint between sphere-like part of the sleeve

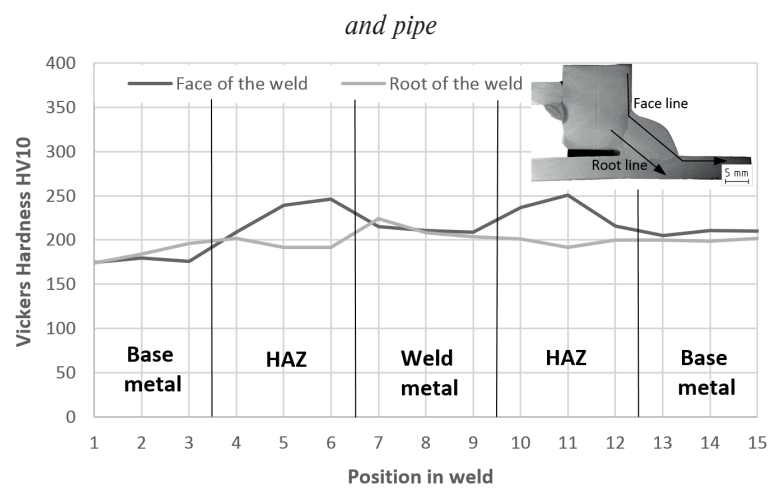

Fig. 9 Hardness of fillet weld joint between cylindrical part of the sleeve and pipe

\subsection{Approval of the sphere-like part base metal chemical composition and mechanical properties}

Macrostructural analysis and hardness measuring pointed out to possibility of insufficient base metal quality or to material interchange of sphere-like part of the split sleeve. Chemical composition, tensile properties and impact toughness of base metal were thus analyzed to prove material quality.

Comparison of the spectral analysis results, attest values and standardized chemical composition according to data sheet are shown in Table 1. Measured values show higher carbon level

Results of spectral analysis compared to semi-product attest and material data sheet (wt. \%)

Table 1

\begin{tabular}{|l|c|c|c|c|c|c|c|c|c|}
\hline Chemical element & $\mathbf{C}$ & $\mathbf{M n}$ & $\mathbf{S i}$ & $\mathbf{P}$ & $\mathbf{S}$ & $\mathbf{N}$ & $\mathbf{C r}$ & $\mathbf{N i}$ & $\mathbf{C u}$ \\
\hline Spectral analysis & 0.415 & 0.797 & 0.236 & 0.018 & $<0.01$ & - & 0.088 & 0.095 & 0.019 \\
\hline Semi-product attest & 0.14 & 0.68 & 0.35 & 0.013 & 0.009 & - & 0.5 & 0.09 & 0.1 \\
\hline Data sheet & max. 0.27 & max. 1.70 & max. 0.60 & max. 0.055 & max. 0.055 & max. 0.011 & - & - & - \\
\hline
\end{tabular}

Comparison of tensile properties after measuring and values from material data sheet

Table 2

\begin{tabular}{|l|c|c|c|}
\hline & Yield strength $\mathbf{R}_{\mathrm{eH}}[\mathrm{MPa}]$ & Tensile strength $\mathbf{R}_{\mathrm{m}}[\mathrm{MPa}]$ & Elongation $\mathbf{A}_{\mathbf{5}}[\mathrm{MPa}]$ \\
\hline Tensile test & 332 & 516 & 3 \\
\hline Data sheet values & 275 & $450-630$ & 17 \\
\hline
\end{tabular}


detected by spectral analysis compared to semi-product attest, which exceeds maximal allowable value defined in material data sheet of S355JR steel.

Ultimate tensile strength, Yield strength and elongation were measured by tensile testing procedure according to directions of EN ISO 6892-1 standard. Three tensile specimens with diameter of $10 \mathrm{~mm}$ were prepared and loaded to fracture at the ambient temperature of $20^{\circ} \mathrm{C}$. Comparison of average value after measuring and values from material data sheet of S355JR steel is shown in Table 2.

Tensile strength and Yield strength correspond with data sheet requirements but elongation obtained from tensile test is evidently lower.

Charpy pendulum impact test was used to determine impact toughness of the sphere-like part of the sleeve material. Conditions of the testing method are defined in the international standard EN ISO 148-1. Experimental samples with V-notch, cross-section size of $10 \times 10 \mathrm{~mm}$ and $55 \mathrm{~mm}$ length were used to testing. Measuring of impact energy was performed at ambient temperature $-20{ }^{\circ} \mathrm{C}$. Average value of impact energy $\mathrm{KV}$ obtained by three measures is $6.7 \mathrm{~J}$ while required value is minimum $27 \mathrm{~J}$. Material thus does not satisfy impact toughness.

\subsection{Evaluation of the base metals microstructure}

Microstructure analysis was performed in order to verify microstructure of the sphere-like part of the split sleeve. Characteristic microstructure of sphere-like part of the sleeve is shown in Fig. 10. Microstructure is formed by large perlite grains surrounded by ferritic envelopes. Base metal microstructure of the cylindrical part of the split sleeve (Fig. 11) is fine-grained ferriticpearlitic and corresponds with S355 grade steel quality.

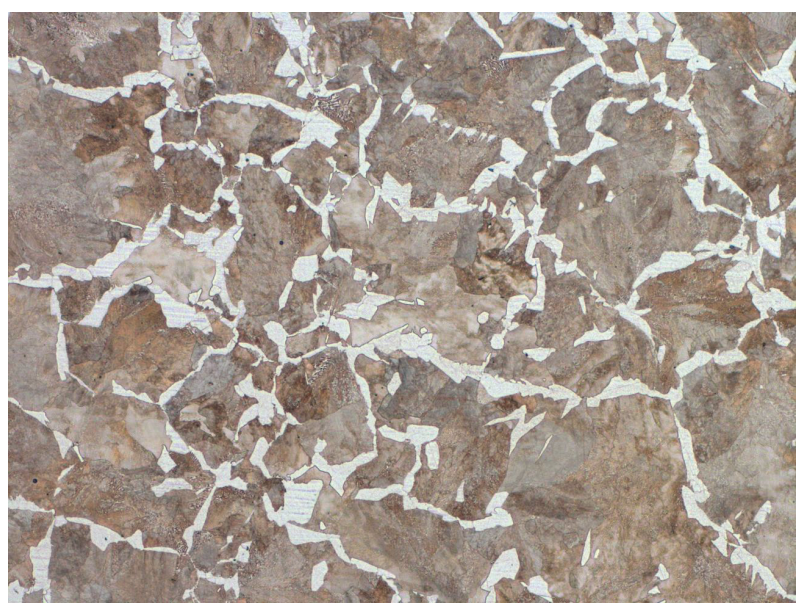

Fig. 10 Microstructure of the sphere-like part of the sleeve, etch. $5 \%$ Nital

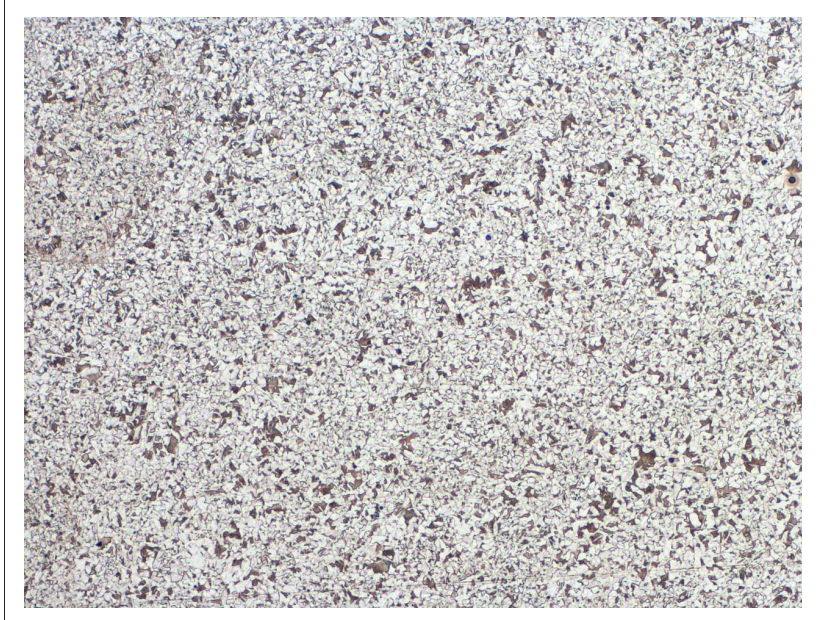

Fig. 11 Microstructure of the cylindrical part of the sleeve, etch. $5 \%$ Nital

\section{Discussion}

Macrostructural analysis and hardness evaluation of the weld joints of split sleeve for branch connection repairs was performed on four characteristic welds. Significant inhomogeneity of the base metal and HAZ on cylindrical and sphere-like side of the weld was observed during macrostructural analysis. This fact was approved by followed microstructural evaluation (coarse-grained pearlitic structure of sphere-like part base metal).

As the microstructure of the sphere-like part of the sleeve does not correspond with assumed structure of applied material, chemical composition and selected mechanical properties were analyzed. Spectral analysis revealed higher carbon level ( 0.47 wt. \%), which exceeded limit value given by material data sheet. However, amount of carbon corresponded with material structure. Measured values of tensile and yield strength were between the standardized value interval for S355JR steel but ductile properties (elongation and impact toughness) were below the limits.

Higher carbon level leads to significant increase of the hardness (up to $378 \mathrm{HV}$ ), especially in fillet welds with increased heat transfer to the wall of the sphere-like part of the sleeve. Welding and cooling conditions then lead to increased cooling rate in HAZ of the fillet weld on the sleeve side and increasing of the Vickers hardness. This effect together with material structure sensitive to hard and brittle phase formation may cause exceeding of the hardness tolerance.

\section{Conclusions}

Results of the presented analysis pointed to low quality of base metal used to sphere-like part of the sleeve manufacturing. Two possible reasons might be taken into account as follows: 
(1) Interchange of the material for steel with higher carbon level in the whole volume of the semi-product.

(2) Material inhomogeneity of semi-product after manufacturing. Steel block with dimensions of $400 \times 800 \times 400 \mathrm{~mm}$ was used to manufacturing. Such kind of semi-product is commonly used to forming operation. As cast microstructure of the block can be very inhomogeneous and uneven chemical distribution may be also present.

To prevent similar behavior of the weld joints, there should be performed measurement of chemical composition before machining of the semi-product and/or full annealing of steel block or manufactured part should be applied. Even when some insufficient material properties can be present, repairing technique by split sleeve can be still suitable for commercial application as there were not exceeded hardness limits, no unacceptable defects of weld joint were present and material properties are still sufficient to carry the loading during the operational time of the sleeve.

\section{Acknowledgement}

This work has been supported by Scientific Grant Agency of Ministry of Education of the Slovak Republic, grants VEGA 1/0610/12 and KEGA 034ŽU-4/2015. Authors acknowledge the grant agency for support.

\section{References}

[1] EUROPEAN GAS PIPELINE INCIDENT DATA GROUP (EGIG): Gas pipeline Incidents. 9th Report of the European Gas Pipeline Incident Data Group (period 1970 - 2013), 2014.

[2] BATISSE, R.: Review of Gas Transmission Pipeline Repair Methods. Safety, Reliability and Risks Associated with Water, Oil and Gas Pipelines. Dordrecht: Springer, 2007.

[3] MICIAN, M., PATEK, M., SLADEK, A.: Concept of Repairing Branch Pipes on High-pressure Pipelines by Using Split Sleeve. Manufacturing Technology, vol. 14, No. 1, 2014.

[4] MESKO, J., FABIAN, P., HOPKO, A., KONAR, R.: Shape of Heat Source in Simulation Program SYSWELD Using Different Types of Gases and Welding Methods. Strojirenska technologie, No. 5, 2011.

[5] PATEK, M., KONAR, R., SLADEK, A., RADEK, R.: Non-destructive Testing of Split Sleeve Welds by the Ultrasonic TOFD Method. Manufacturing Technology, vol. 14, No. 3, 2014. 